\title{
Cardiovascular magnetic resonance stress perfusion imaging in patients with atrial fibrillation
}

\author{
Thomas Hucko ${ }^{1 *}$, Christoph Klein ${ }^{1}$, Bernhard Schnackenburg ${ }^{2}$, Christopher Schneeweis ${ }^{1}$, Sebastian Kelle ${ }^{1}$, \\ Alexander Berger ${ }^{1}$, Eckart Fleck', Rolf Gebker ${ }^{1}$ \\ From 16th Annual SCMR Scientific Sessions \\ San Francisco, CA, USA. 31 January - 3 February 2013
}

\section{Background}

Several studies have demonstrated the consistently high diagnostic and prognostic value of adenosine stress perfusion imaging with cardiovascular magnetic resonance (CMR). The feasibility and diagnostic accuracy of CMR stress perfusion in patients with atrial fibrillation is unknown. The purpose of this study was to assess the utility of CMR stress perfusion imaging in patients with atrial fibrillation who had suspected and known coronary artery disease (CAD).

\section{Methods}

Thirty-eight patients with suspected myocardial ischemia underwent adenosine stress and rest perfusion CMR (bSSFP, TE/TR/alpha $1.3 \mathrm{~ms} / 2.5 \mathrm{~ms} / 50^{\circ}$, 3 slices/heartbeat, voxel size $2.9 \times 3.0 \times 10 \mathrm{~mm})$ and late gadolinium enhancement (LGE) imaging (free breathing single shot, bSSFP, TE/TR/alpha $1.6 \mathrm{~ms} / 3.1 \mathrm{~ms} / 50^{\circ}$, voxel size $1.8 \mathrm{x}$ $1.9 \times 10 \mathrm{~mm}$ ) at $1.5 \mathrm{~T}$. All scans were examined by two independent readers. Image quality was assessed on a 4point scale ( $1=$ =xcellent, $2=$ good, $3=$ moderate, $4=$ nondiagnostic). Segmental perfusion and LGE images were evaluated for stress induced myocardial ischemia. Perfusion deficits were compared with the results of invasive coronary angiography on both a patient and coronary territory basis. Patients not undergoing invasive coronary angiography were followed up for adverse cardiac events (PCI, CABG, myocardial infarction, cardiac death).

\section{Results}

All patients were examined successfully. Mean image quality of perfusion was $1.73 \pm 0.61$. Patient- and territory-based inter-observer variability was very low ( $\kappa=0.94$ and 0.89 , respectively). LGE indicating prior myocardial infarction was present in 12 patients with a mean image quality of $2.16 \pm 0.69$. All patients $(n=9)$ with stress inducible perfusion deficits underwent invasive coronary angiography. A coronary stenosis $\geq 50 \%$ was found in $8(89 \%)$ patients. Of these, $7(78 \%)$ had a stenosis $\geq 70 \%$. Seven patients underwent invasive angiography despite negative CMR perfusion. Of these, 2 had stenosis $\geq 50 \%$ and none had stenosis $\geq 70 \%$. The remaining 22 perfusion negative patients were followed up for a mean of $14 \pm 7$ months (median: 12.9 months). None of these patients experienced a major cardiac event.

\section{Conclusions}

In patients with atrial fibrillation, CMR stress perfusion can detect $\mathrm{CAD}$ with good image quality and low interobserver variability. CMR perfusion imaging may offer an alternative method of detecting ischemia for the purpose of risk stratification and guiding revascularisation in patients with atrial fibrillation.

\section{Funding}

None. 

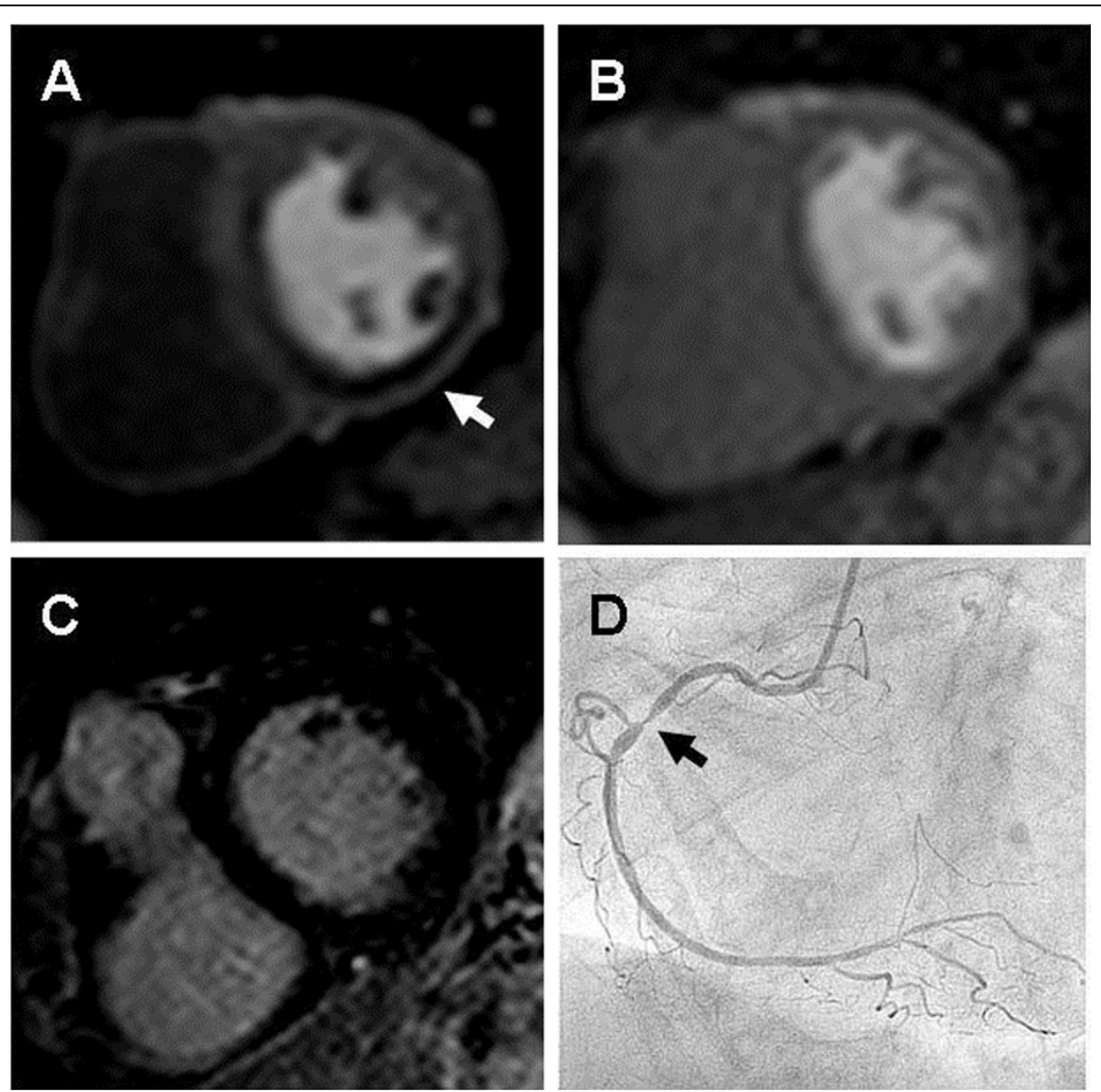

Figure 1 A: basal short axis view with perfusion deficit at stress (arrow), B: basal short axis view without perfusion deficit at rest, C: basal short axis view without late gadolinium enhancement, D: invasive coronary angiography with significant stenosis of proximal RCA (arrow).

\section{Author details}

'Internal Medicine - Cardiology, German Heart Institute Berlin, Berlin, Germany. ${ }^{2}$ Philips Health Care, Hamburg, Germany.

Published: 30 January 2013

doi:10.1186/1532-429X-15-S1-E59

Cite this article as: Hucko et al:: Cardiovascular magnetic resonance stress perfusion imaging in patients with atrial fibrillation. Journal of Cardiovascular Magnetic Resonance 2013 15(Suppl 1):E59.

\section{Submit your next manuscript to BioMed Central} and take full advantage of:

- Convenient online submission

- Thorough peer review

- No space constraints or color figure charges

- Immediate publication on acceptance

- Inclusion in PubMed, CAS, Scopus and Google Scholar

- Research which is freely available for redistribution 